\title{
Longing for the Past: An Analysis of Discursive Formations in the Greta Thunberg Message
}

\author{
By Hanna Sjögren
}

\begin{abstract}
This article studies discursive formations of climate change in texts by the contemporary climate activist movement's most famous character, Greta Thunberg. This study critically analyses the Greta Thunberg message and discusses the kind of worlds her message evokes. In doing so, the author discusses what is being included in and omitted from contemporary public understandings of climate change. Three themes are identified and analysed in the Greta Thunberg message: science as truth; for the sake of the human child; and the apocalyptic futures and the evocation of the past. It is argued that the Greta Thunberg message makes sense because of how it resonates with a worldview related to the promises of modernity. Furthermore, one way of understanding the popularity of Thunberg's message is that it evokes dreams of a world that once was. It is suggested that the Greta Thunberg message evokes longing for the past, rather than the possibility of existing in an already changing climate. ${ }^{1}$
\end{abstract}

Keywords: Climate change, discursive formations, modernity, time, Greta Thunberg.

Hanna Sjögren: "Longing for the Past: An Analysis of Discursive Formations in the Greta Thunberg Message", Culture Unbound, 2020: XX-XX. Published by Linköping University Electronic Press: http://www.cultureunbound.ep.liu.se 


\section{The Global Circulation and Formations of Climate Discourses}

Climate change is part of contemporary sense-making about the world. It is even argued that the climate holds a hegemonic position in how we imagine social life and the future of the human species (Hulme 2011). Scientists and activists now advocate for the necessity of rapid transformation to reduce global warming based on both scientific knowledge and moral reasoning. Behind these claims lies a shared concern for the Earth and its inhabitants (Edwards 2010). A recent movement in this vein is Fridays for Future which conducts the school climate strike, with protests including skipping school once a week. The movement was inspired by the 15-year-old climate activist Greta Thunberg. Since 2018, this movement has demanded political action to reduce greenhouse gas emissions and slow rising temperatures. These demands combine political subjects and knowledge to make claims that appear reasonable and rational. In what follows, I refer to these relationships and claims as the discursive formations of climate change (cf. Anshelm \& Hultman 2015; Kverndokk 2020; Wetts 2020). My use of discursive formations draws on Michel Foucault's (1972: 38) explanation to describe regularity and order "between objects, types of statement, concepts, or thematic choices." Foucault wrote that the rules of discursive formations comprise the condition of existence to which objects, types of statement, concepts, and thematic choices are subjected. Discursive formations in Foucault's writings "work to make speech possible, organize ideas and concepts, and produce 'objects of knowledge"' (Danaher et al. 2000: 22). I use the notion of discursive formations to refer to and analyse statements that produce seemingly stable objects of knowledge in the Greta Thunberg message that has inspired the global climate strike.

In this article, I take a closer look at the relationships between political subjects and knowledge in claims about climate change. I analyse the discursive formations of climate change in texts written by Fridays for Future's most famous spokesperson, Greta Thunberg. To date, Thunberg has been an invited speaker at global events hosted by organizations such as the United Nations, the European Union, and the World Economic Forum. In other words, the Greta Thunberg message has reached influential audiences. How can we understand why Thunberg's message is gaining such popularity?

I critically analyse discursive formations embedded in the Greta Thunberg message and I discuss the kind of worldview they evoke. In doing so, I discuss what is being included in and omitted from contemporary public understandings of climate change. However admirable and righteous Greta Thunberg's cause and the global climate movement might be, I suggest that there are reasons for scholarship to ask critical questions even about projects setting out with the best of intentions (see e.g Hulme 2011; Ideland 2019; Qvarsebo 2019). What we tend 
to take for granted as the given good is, arguably, what critical scholars should address. In other words, whenever a problem is presented as the only problem we should care about, critical scholars should ask what problems we are ignoring in our quest for the common good. In line with previous scholars who advocate for a critical engagement with environmental issues, I agree that social science should "prompt scholars to reflect upon the ideas, norms and power relations that make up the world" (Lövbrand et al. 2015: 212).

In Edwards' (2010) work on the history of climate science, he argues that global thinking has emerged in language, ideology, technology, and practice since World War II. The very possibility of thinking about the Earth as a whole is a consequence of scientific progress and invention. In line with Edwards, I argue that how climate change is spoken of forms our understanding of the world. Furthermore, claims and assumptions can always be understood otherwise. Similar to Edwards (2010: 1), I maintain that slogans for action in relation to the climate capture "an entire philosophy, complete with ontology, epistemology, and ethics". Critical reflections on what is being omitted and for whom particular formations matter can be pinpointed when studying how the world is represented in speeches about climate change. Formations of the world can never be innocent because they must always be told by including some things and by leaving other things out.

The academic context of this article is the scholarly discussion around what it means to be human in a warming climate (Gabrys \& Yusoff 2012; Haraway 2015; Neimanis et al. 2015; see e.g. Neimanis \& Walker 2014). I draw on scholarship that grapples with how to make sense of uncertainties and threats in contemporary societies (see e.g. Alaimo 2010; Bauman 2000, 2017; Beck 1992, 1995), more specifically, scholarship that engages with the relationship between discourse and public understandings of climate and environmental change (Anshelm \& Hultman 2015; Hulme 2011; Kverndokk 2020; Lövbrand et al. 2015). This area of research is significant because of "the disjuncture between ways of talking about uncertainty within science and policy discourse and media constructions of objectivity, truth, and balance" (Smith 2005: 1471). According to Lövbrand et al. (2015), engagement with the stories told about the Earth today should be imperative for social scientists. The authors suggest three entry points into this engagement: a radicalized understanding of nature as post-natural, with a research agenda fostering scholarship considering how the concept of nature is represented and how these representations become tied to certain solutions; a highlighting of social diversity and difference by researchers who resist universal accounts of humanity but instead situate people and communities in their contexts as shaped by power relationships; and a reintroduction of the political into scholarly engagement with environmental change by rethinking engagement with nature as a space for political struggle, and by asking questions about what kind of societies 
we want. These calls point towards critical engagement with how humans relate to climate change today. This article contributes to critical scholarship in this vein.

The article began with a theoretical account of the role of discourses in making sense of climate change. In what follows, the concept of discourse formations is also related to three different world views; modernity, postmodernity and reflexive modernity. The article continues with a section justifying the material and method used in analysing the Greta Thunberg message. The analysis is then presented in the form of three themes identified in the Greta Thunberg message: science as truth; for the sake of the human child; and apocalyptic futures and the evocation of the past. The article ends with a concluding section where I argue that the Greta Thunberg message can be read as a counter-discourse to the message of the alarming state of the Earth, in which the human species has lost all its sense of control.

\section{Exploring the Worldviews in the Greta Thunberg Message}

In this section, I introduce the analytical approach for this article. In tracing recurring discursive formations in the Greta Thunberg message, I analyse these formations in relation to three grand conceptualisations or worldviews: modernity, postmodernity, and reflexive modernity. I first ask which discursive formations appear in the Greta Thunberg message, and secondly how these formations relate to ways of viewing the world (i.e. worldviews). In what follows, I use simplified definitions of complex ideas; but I am not alone in trying to capture and say something about the grand but changing structures in worldviews and systems of thinking (e.g. Bauman 2000; Beck 1992, 1995; Beck et al. 2003; Giddens 1991; Hannigan 1995; Harvey 1990; Hulme 2011; Jenks 2005). These definitions of worldviews are particularly significant in studies of environmental and climate change (Beck 1992, 1995; Hannigan 1995).

In brief, modernity stems from the Enlightenment, where rational thinking and objective knowledge, as well as a firm belief in both control and progress, are central aspects. The modern project unfolded in the Western world starting around the 1700s, with ideals including objective knowledge and universal morality (Harvey 1990). Linearity, continuity, and truth are other imperatives of the modern project. The modern understanding of progress constructs time as universal and linear (Edwards 2010). In this article, modernity is defined as a linear understanding of continuous progress in both knowledge production and technical development where the future is seen as bright.

Postmodernity, on the other hand, questions most of the assumptions of the modern era. Time, knowledge, and truth are seen as malleable and socially constructed. These postmodern ideas have led to a fundamental critique of the 
ideals of linearity, continuity, and truth within modernity (Harvey 1990). The postmodern understanding of time is multilayered, ad hoc, and unpredictable. Postmodernity is defined as a discontinuity that includes the nonlinear unfolding of events with unforeseen and uncertain consequences.

Reflexive modernity is a third worldview that describes the relation between knowledge, nature and society in our time of environmental degradation (Beck et al. 2003). Beck (1992) coined the related term "risk society", which signifies a society that both suffers from, and is dependent on, scientific progress. The term reflexive modernity suggests a kind of revised and updated form of modernity, where scientific knowledge has a role to play, albeit a role of which one must be skeptical. Hannigan (1995: 181) suggests reflexive modernity as a 'middle way' between modernity and postmodernity. In the words of Beck et al. (2003: 3): "[s]imple modernization becomes reflexive modernization to the extent that it disenchants and then dissolves its own taken-for-granted premises." In short, reflexive modernity acknowledges that we know that our way of living and organizing society is fragile, but that it is all we have. One might call reflexive modernity a modernity with hesitation.

It is probably fair to say that these different worldviews or systems of thinking exist side by side today, not least as traces and material manifestations interwoven in stories, ideas, architecture, politics, and our collective imagination. The purpose of sketching out these models is to study how the claims and demands in the Greta Thunberg message bring together relationships between political subjects and knowledge that make the claims reasonable and rational. I suggest that the use of worldviews is a productive analytical lens for studying the message conveyed by Greta Thunberg.

\section{Analysing the Greta Thunberg Message}

In this article, I take a close look at discursive formations of climate change by Greta Thunberg. Although Thunberg is often described as a role model with "heroism and iconicity" (Bergmann and Ossewaarde 2020: 17), her speeches can be analysed in broader terms because of how they have resonated with audiences globally (Kverndokk 2020). I conducted a close reading of the 11 texts published in the collection No one is too small to make a difference (Thunberg 2019). These texts are analytically valuable because of the worldwide audience they have reached though both traditional and social media. Thousands of articles have been written globally about Thunberg and the school climate strike over the last year (retrieved from newsbank.com August 27, 2020). Because of the reach Thunberg's texts have had and still have, they represent how discourses around climate change are formed in our world today. 
My intention here is not to deconstruct the ideas written by the person Greta Thunberg; rather, the point of interest is the texts themselves, and what features in them might have resonated with such large audiences. I use Thunberg's speeches as "data object[s]" (Moezzi et al. 2017: 1) for analysis. Moreover, I use the notion of 'the Greta Thunberg message' to emphasize that the research interest in this article is not Greta Thunberg as a person, but the discursive formations in the message told by her. I have chosen not to focus on the context in which the message is told as this has been done by others (Bergmann and Ossewaarde 2020; Kverndokk 2019, 2020).

I coded the material analysed below in three stages. In the first stage of coding, I categorized passages from the texts under descriptive and multiple labels (e.g., 'corporations', 'crisis', 'homo sapiens', 'inaction', 'school', and 'panic'). I conducted the first stage to get an overview of the themes occurring in the speeches. In the second stage, I coded the texts using larger and more abstract categories in the form of clusters (e.g., 'children' and 'adults'). In the last stage, I formed the following seven recurrent descriptive categories: science, ignorance, injustice, age, nature, disasters, and school strike. All categories were considered for further analysis, but the final analysis was conducted by a close reading of the categories 'science', 'age', and 'disasters'. Based on the focus on discursive formations, I found these three categories to be most significant for the formations, and all three categories included traces of worldviews. I chose these categories to critically analyse the Greta Thunberg message and to discuss the kind of world her message evokes. The quotations presented below were chosen because they represent both reoccurring threads in the Greta Thunberg message and differences within the themes.

The sections below are divided according to the three significant and analytical themes of the Thunberg message, with a focus on discursive formations. The first analytical section on science presents an analysis of how science is used to mobilize a mostly modern formation of scientific progress and certainty. The second analytical section focuses on how a discursive formation mobilizes the human child as a way to reinstall human mastery. The third section on apocalyptic futures analyses how the formation mobilizes some traditional values of modernity.

\section{Science as Truth}

The Greta Thunberg message about climate change repeatedly relies on a natural science account of the climate. All of Thunberg's speeches and texts include seemingly precise references to climate and natural science. For example, the message declares the exact number-200-of species becoming extinct every day (Thunberg 2019: 9). In the following quotation, it is obvious that the Thunberg message uses scientific estimates to claim certain trajectories for the changing climate: 
Around the year 2030, 10 years, 259 days and 10 hours away from now, we will be in a position where we will set off an irreversible chain reaction beyond human control that will most likely lead to the end of our civilization as we know it. (Thunberg 2019: 46)

Both certainty and uncertainty are evoked in the passage above. The exact number of years, days, and hours from when the speech was given (in Strasbourg on April $16,2019)$ until the outset of an irreversible chain reaction are mentioned, relying on universal time as an exact measurement of the relationship between events. Universal time is one of the core infrastructures of modernity (Edwards 2010). On the other hand, the word "around" at the beginning of the quotation indicates that the calculation is not as certain as might at first seem. That humans are "most likely" to set off reactions that will end our civilization, i.e., what we have come to think is normal for organizing society, leaves us with a message of unknown consequences. In this way, the Thunberg message, with the use of climate science, highlights both the known and unknown of scientific knowledge. This formation evokes a reflexive modernity of both trust and scepticism in relation to science. The unknown is, however, said to be avoidable if the right measures are taken. The thread continues:

That is, unless in that time permanent and unprecedented changes in all aspects of society have taken place, including a reduction of our $\mathrm{CO} 2$ emissions by at least 50 per cent. And please note that these calculations are depending on inventions that have not yet been invented at scale, inventions that are supposed to clear our atmosphere of astronomical amounts of carbon dioxide. Furthermore these calculations do not include unforeseen tipping points and feedback loops, like the extremely powerful methane gas escaping from rapidly thawing Arctic permafrost. (Thunberg 2019: 46-47)

The message told above can be read as both alarming and comforting, containing both hope and fear (see e.g. Dahlbeck 2014). Alarming, because according to climate science, unforeseen tipping points and feedback loops will be set off by the already warming climate. Comforting, because there is time to make changes in society, including reducing carbon dioxide emissions, and because there are inventions that can clean the atmosphere. The message seems to be that if we only trust science, we humans can be saved as a species. I read this as an idea belonging to modernity of control and linearity. In the following quotation, it is even clearer that we humans, despite the uncertainty, should rely on science as a truth teller and saviour: 
We must also bear in mind that these are just calculations, estimations, meaning that the point of no return may occur a bit sooner or later than that. No one can know for sure. We can however be certain that they will occur approximately in these time-frames. Because these calculations are not opinions or wild guesses. These predictions are backed up by scientific facts, concluded by all nations through the IPCC. (Thunberg 2019: 47-48)

The international consensus is evoked to support the predictability of scientific facts. Even though science can only offer calculations and estimations, as suggested by Beck (1992), the message still claims that it is certain that "the point of no return" will occur "sooner or later". There is no question that science is what we must rely on to be saved from passing the point of no return. In another speech, Thunberg (2019: 55) addresses the British Parliament "on behalf of future generations", claiming that the children are only "repeating the message of the united climate science". This point is emphasized elsewhere when it is argued that science should become the heart of politics and democracy: "I keep telling you [i.e., politicians] to unite behind the science. Make the best available science the heart of politics and democracy" (Thunberg 2019: 52).

How science can become the heart of politics is spelled out below:

... the only thing that we need to look at is the emission curve. And I'm sorry, but it's still rising. That curve is the only thing we should look at. Every time we make a decision we should ask ourselves: how will this decision affect that curve? We should no longer measure our wealth and success in the graph that shows economic growth, but in the curve that shows the emissions of greenhouse gases. (Thunberg 2019: 64)

In the second quotation above, it is claimed that our human existence should rely on our relationship to the emission curve, and that not much else matters. The message puts the curve at the centre of attention, making it the measure against which everything else should be compared. The curve further puts climate science at the centre of the world and global decision-making. The models and estimates made by climate science produce a message-and a reality - in which decisions should always be made in relation to how they affect the emission curve. Hulme (2011: 245) has named this faith in climate science when predicting the future a "climate reductionism." The climate thus becomes the main source for explaining almost everything that is happening in contemporary societies. Listening to science seems to be the way politicians and adults can give children a future: "I assure you we [children] will go back to school the moment you start listening to science and give us a future. Is that really too much to ask?" (Thunberg 2019: 57). 
Is it too much to ask, just to listen to science? Thunberg's message is supported by world-scale infrastructures that make possible certain types of knowledge and communication that involve material artefacts such as satellites, electric power, and servers of data and signals (see e.g. Edwards 2010). Science has made possible various inventions that have contributed to large-scale greenhouse gas emissions, but these effects of science are left out of the discursive formations here. As critically argued by Lövbrand et al. (2015: 212), the current mainstream understanding of Earth's changing climate has "foreclosed the conversation on the range of social and environmental futures that are possible". In my interpretation, the unconditional trust in climate science can be read as belonging to a discursive formation drawing on modernity, in which truth and certain knowledge are possible. This understanding does not allow for a multiplicity of truths and knowledges that the postmodern position would evoke. A strong belief in science lies at the heart of the modern project.

Lyotard (1986: xxiii-xxiv) claimed that the modern condition of knowledge has been legitimized "with reference to a metadiscourse ... making an explicit appeal to some grand narrative" in which "the hero of knowledge works toward a good ethico-political end-universal peace". In his diagnosis of the postmodern condition, knowledge claims are plural, uncertain, and fragmented. One question that this diagnosis suggests concerns how scientific knowledge can be legitimized (see e.g. Strandbrink 2018). The Greta Thunberg message paints a broad and simplified picture of scientific findings about the climate, findings that always come from socially constructed, complex measurements and estimations (see e.g. Edwards 2010). In Edward's analysis, climate science does not exist 'naturally', but needs to be created from socially constructed and shared knowledge drawn from various standards and sources. The Greta Thunberg message can be read as a mostly modern discursive formation of the role of science as a producer of good and certain knowledge that we all can trust.

\section{For the Sake of the Human Child}

Another important theme in the Greta Thunberg message is that of human mastery. The message seems to be that we humans can still be the masters of the planet if we act in time. Thunberg's message rests, for the most part on modernity's certainty and assumptions about the relationship between humans and their surroundings. The planet is supposedly in the hands of humans:

But Homo sapiens have not yet failed. Yes, we are failing, but there is still time to turn everything around. We can still fix this. We still have 
everything in our own hands. But unless we recognize the overall failures of our current systems we most probably don't stand a chance. We are facing a disaster of unspoken sufferings for enormous amounts of people. (Thunberg 2019: 20)

In the quotation above, humans as a unified category are assumed to have absolute control over the situation. The message seems to be that it is we who have caused these changes in the climate, and it is also we who can change the situation. The threat of suffering is assumed to happen to humans. It is worth pointing out that what sustains the people, i.e., the environment in which we live, is not mentioned in the message. The message seems to assume that humans exist outside of the climate and "relate to the globe as the milieu for [human] survival" (Colebrook 2009 quoted in Neimanis \& Walker 2014: 567). This message reinforces the idea, central to the modern understanding, of a divide between humanity and nature. Beck (1995: 37) noted that the idea of nature is one of nostalgia and myth: "work, production, government and science at once reconstruct [nature] and furnish it with the norms by whose yardstick it is judged to be endangered and damaged". Central to Beck's argument is that there is no pure nature that is unaffected or outside of human culture. A similar and more recent argument has been made around the concept of the Anthropocene, defined as a geological epoch caused by the impact of the human species on the Earth's geology and ecosystems, including anthropogenic climate change (see e.g. Bird Rose et al. 2012; Waters et al. 2016). However artificial or 'unnatural' our surrounding environment might be, the idea of nature still strongly resonates with ideas that seem to express longing for what once was.

When the Greta Thunberg message justifies to audiences of politicians why rapid transformations are needed, children, grandchildren, and the beautiful planet are listed as reasons for bringing about change: "I ask you to prove me wrong. For the sake of your children, for the sake of your grandchildren. For the sake of life and this beautiful living planet" (Thunberg 2019: 18). Bringing together children and nature is a central relationship through Western history and philosophy (see e.g. Archard 2015; Halldén 2011; Ideland 2019; Jenks 2005; Kverndokk 2020). In Western philosophy, Rousseau (1712-1778) was and still is highly influential, describing children as innocent and close to uncorrupted nature; a way of thinking about children that remains with us today (Archard 2015). The message contains a modern and coherent formation of what we should value in times of pressing climate change. The formation of the innocent and pure child enables a tale of rescuing the precarious one and establishes an understanding in which adult, human decision-makers still can be heroes. 
The following quotation further emphasizes that the choice over the future course of events is in the hands of human civilization:

Either we prevent $1.5^{\circ} \mathrm{C}$ of warming or we don't. Either we avoid setting off that irreversible chain reaction beyond human control or we don't. Either we choose to go on as a civilization or we don't. (Thunberg 2019: 21)

Preventing 1.5 degrees Celsius of warming is said to be possible if we humans choose to avoid it. This formation constructs how adults can chose to save children and civilization, if they only do things right. Again, what is being told is a reassuring message of certainty and human mastery that might be appealing because hope can be invested in a modern worldview of control and stability. The solution to the crisis also seems natural and feasible, if politicians only were to think more like children:

Solving the climate crisis is the greatest and most complex challenge that Homo sapiens have ever faced. The main solution, however, is so simple that even a small child can understand it. We have to stop our emissions of greenhouse gases. And either we do that or we don't. (Thunberg 2019:21)

However complex the climate crisis, the message told is that the solution is simple, even an issue of "black and white" (Thunberg 2019:8). In my interpretation, calling for the complete stopping of greenhouse gas emissions creates a formation that evokes a grand modern worldview in which change can be made from a point of unity. It is reasonable to interpret this formation as one that puts forward a dream of what once was. The message might evoke a longing for a lost unified society (see e .g. Bauman 2017). As previously outlined, this formation can be understood as the longing for a stable ground where time has not been able to transform or change the conditions of possibility. The formation of the Greta Thunberg message is clear: we are currently not on the right path, and we-as humans and as a civilization-have to change. I suggest that the proposed change is pointing in the direction of ideas of what once was. It can be interpreted as "a nostalgia for the future" (Davies 2010: 264) in which the present is the time to which the imagined future will always refer, in order to create the image of a satisfactory home. It is reasonable to believe that the longing for the past can be read as a reaction to a fragmented reality in which identities and truths are fluid and negotiable. Bauman (2017: 153) has written that our age is one "in which everything — or almost—may happen, while nothing—or almost—can be 
undertaken with self-assurance and with certainty of seeing it through" (153), and this is, he claims, "anything but pleasurable, soothing and gratifying" (154-155). In my understanding, it is in light of this condition that our collective longing for the past as the ideal future makes sense. It is also in light of this present condition of longing for the past as the ideal future that we can understand why the Greta Thunberg message might be so appealing and so popular. The Greta Thunberg message leaves us with a sense of that we can return to a past when the future was bright, and the human species was on a victory parade of endless progress.

\section{Apocalyptic Futures and the Evocation of the Past}

A common theme in the Greta Thunberg message is that of the near apocalypse. Thunberg's message commonly uses words such as "panic", "fear", and "crisis". In the following quotation, Thunberg's message tells about how action is needed in order to give children a future:

The future of all the coming generations rests on your [adult] shoulders. Those of us who are still children can't change what you do now once we're old enough to do something about it. ... So please, treat the climate crisis like the acute crisis it is and give us a future. (Thunberg 2019: 4-5)

What awaits coming generations is an acute crisis and the scenario of no future at all. It is clear that through a different course of human action, it is possible that "past, present, and future [can] constitute progressive steps toward a better world, a set future that we can achieve through human perseverance" (Neimanis and Walker 2014: 568 italics in original). In other words, the formation of the apocalypse is mobilized to make another formation possible-that of possible changes and possible futures-which follows the linearity of universal time and modernity's progress. Set against the threat of the apocalypse, it seems reasonable to give coming generations of humans a future. Furthermore, the Greta Thunberg message uses the legacy of achievements and progress in order to communicate how climate change should be understood:

We need to focus every inch of our being on climate change, because if we fail to do so then all our achievements and progress have been for nothing and all that will remain of our political leaders' legacy will be the greatest failure of human history. (Thunberg 2019: 37) 
This formation constructs the apocalypse as indicating that our civilization has failed. The message told promises the possibility of achievement and progress. This formation recalls the dream of the modern project, in which "the genuine or putative aspects of the past, [are] believed to be successfully tested and unduly abandoned or recklessly allowed to erode" (Bauman 2017: 9).

A relation of temporality between the past, present, and future is produced through the Thunberg message. In this way, the formation connects different temporalities that create a type of "nostalgia" for the future by constructing a continuity between the past, present, and future. The formation is also a tale of time, evoking the ongoing life of the child-rearing family and the importance of maintaining one's home, telling, for example, of future birthdays to be celebrated with children and grandchildren. This formation features the role of the traditional child rearing family and a stable home in the future to come. As noted by Davies (2010), nostalgia can be understood as suffering the loss of a homecoming. Unlike the adults in the Greta Thunberg message, the child is constructed as someone who would love her children by giving them a future:

The year 2078 I will celebrate my seventy-fifth birthday. If I have children, then maybe they will spend that day with me. Maybe they will ask about you. Maybe they will ask why you didn't do anything, while there still was time to act. You say that you love your children above everything else. And yet you are stealing their future. (Thunberg 2019: 16)

In the message above, the word "maybe" is used to denote possibility-what may, or may not, be. With real love, according to the message, it is possible to give coming generations of children a future that resembles the past. This formation creates a timeline of continuity. Not being able to have an adulthood without sorrow is also added to the formation of a desirable future. The potential for young people to be continuously carefree is touched on in the message below:

In the year 2030 I will be twenty-six years old. My little sister, Beata, will be twenty-three. Just like many of your own children or grandchildren. That is a great age, we have been told. When you have all of your life ahead of you. But I am not so sure it will be that great for us. (Thunberg 2019: 57-58)

Belief in a promising future is one characteristic of modernity. The message told in the above quotation is one in which children of today will not have what previous generations have had. The happy future seems to belong to the past, unless 
appropriate measures are taken to ensure continuity between past, present, and future.

\section{Concluding Discussion}

The Greta Thunberg message has attracted global attention since the first school climate strike took place in the Swedish capital of Stockholm in August 2018. How can we understand why the Greta Thunberg message has gained such popularity? In this article, I sought to critically analyse the Greta Thunberg message and discuss the kind of world her message evokes. The analyses focused on discursive formations embedded in the Greta Thunberg message and discussed the worldviews the formations evoked. Through a close reading of the claims made in this message, I show that the Greta Thunberg message appeals to traditional values and a longing for an imagined past. Based on the above analysis, I suggest that the Greta Thunberg message makes sense because it is told as a counter-discourse to the current climate change path, by connecting the imagined past with the future. The message can be read as a possible counter-discourse to the formation of the alarming state of the Earth in which the human species has lost all its sense of control.

Climate science plays a double role in this counter-discourse. The references to climate science in the Greta Thunberg message are used to call into question the effects of progress and the rationales of modern society. At the same time, however, climate science is also used in the message to take us back to a modern worldview of scientific knowledge as certain and stable. In this way, the Thunberg message creates continuity between an imagined past and a desired future. The message seems to give the human species a role in order to reassure us that we can still be the masters of the planet, if we act in time. Thunberg's message rests on modernity's certainty and assumptions about the relationship between humans and their surrounding world. This reassuring sense of control might contribute to the popularity of the message. The notion of an apocalyptic future enables a particularly successful formation because it re-enacts certain values of modernity and what we as a species have lost but should strive to regain. This formation of the future includes a nostalgic account of the child-rearing family and a stable home. The formation of the future is oriented towards human action as the only thing that can turn things around-arguably, the same line of thinking that made the modern project, and fossil fuel economy, possible.

The Greta Thunberg message enables us as a species to once again dream big. We can dream big both in terms of what is possible for humans to control, and in terms of regaining access to certainty and optimism. Dreaming big, however, has consequences for what can be included in the Greta Thunberg message. The broad 


\section{Culture Unbound}

Journal of Current Cultural Research

and simplified interpretations of scientific claims in the message excludes the uncertainties and politics which are always part of knowledge claims in natural science (Edwards 2010; Lövbrand et al. 2015) - uncertainties that should not be left to scientists alone (Hulme 2011; Swyngedouw 2010). Also left out are all those entities and phenomena that sustain the human species and make up the very thing we call climate: chemical and biological processes, plants, microorganisms, and nonhuman animals (Alaimo 2010; Neimanis \& Walker 2014).

To conclude, the Greta Thunberg message constructs a longing human subject who mourns a bygone world. The message evokes a longing for the past rather than the possibility of existing in an already changing climate. It enables us to navigate a world of climate change by evoking a dream of the past that never was.

Hanna Sjögren is Associate Senior Lecturer at the Department of Childhood, Education, Society at Malmö University in Sweden. Her research concerns how people understand and interpret environmental change as an entangled cultural, societal, and scientific phenomenon.

\section{Notes}

1 The author would like to thank her colleagues at the Department of Childhood, Education and Society at Malmö University for encouraging her to write and submit the article. The author would also like to thank the two anonymous reviewers who contributed with insightful and detailed comments on the paper.

\section{References}

Alaimo, Stacy (2010): Bodily Natures: Science, Environment, and the Material Self, Bloomington: Indiana University Press.

Anshelm, Jonas \& Martin Hultman (2015): Discourses of Global Climate Change: Apocalyptic Framing and Political Antagonisms, Abingdon, Oxon: Routledge.

Archard, David (2015): Children: Rights and Childhood, London: Routledge.

Bauman, Zygmunt (2000): Liquid Modernity, Cambridge: Polity.

Bauman, Zygmunt (2017): Retrotopia, Malden, MA: Polity.

Beck, Ulrich (1995): Ecological Politics in an Age of Risk, Cambridge: Polity.

Beck, Ulrich (1992): Risk Society: Towards a New Modernity, London: Sage.

Beck, Ulrich; Bonss, Wolfgang; Lau, Christoph (2003): "The Theory of Reflexive Modernization:Problematic, HypothesesandResearchProgramme," Theory, Culture \& Society, SAGE Publications 20:2, 1-33, doi: 10.1177/0263276403020002001.

Bergmann, Zoe; Ossewaarde, Ringo (2020): "Youth Climate Activists Meet Environmental Governance: Ageist Depictions of the FFF Movement and Greta Thunberg in German Newspaper Coverage," Journal of Multicultural Discourses, 0:0, 1-24, doi: 10.1080/17447143.2020.1745211.

Bird Rose, et al. (2012): "Thinking through the Environment, Unsettling the Humanities," Environmental Humanities, 1, 1-5.

Dahlbeck, Johan (2014): "Hope and Fear in Education for Sustainable Development," Critical Studies in Education, 55:2, 154-169, doi: 10.1080/17508487.2013.839460. 


\section{Culture Unbound}

Journal of Current Cultural Research

Danaher, Geoff, Tony Schirato \& Jen Webb (2000): Understanding Foucault, London: SAGE.

Davies, Jeremy (2010): "Sustainable Nostalgia," Memory Studies, 3:3, 262-268, doi: $10.1177 / 1750698010364819$.

Edwards, Paul N. (2010): Vast Machine: Computer Models, Climate Data, and the Politics of Global Warming, Cambridge: The MIT Press.

Foucault, Michel (1972): The Archaeology of Knowledge and the Discourse on Language, New York: Pantheon books.

Gabrys, Jennifer \& Kathryn Yusoff (2012): "Arts, Sciences and Climate Change: Practices and Politics at the Threshold," Science as Culture, 21:1, 1-24, doi: 10.1080/09505431.2010.550139.

Giddens, Anthony (1991): Modernity and Self-Identity: Self and Society in the Late Modern Age, Cambridge: Polity press.

Halldén, Gunilla (2011): Barndomens Skogar: Om Barn i Natur Och Barns Natur, Stockholm: Carlsson.

Hannigan, John (1995): Environmental Sociology: A Social Constructionist Perspective, London: Routledge.

Haraway, Donna Jeanne (2015): “Anthropocene, Capitalocene, Plantationocene, Chthulucene: Making Kin," Environmental Humanities, 6, 159-165.

Harvey, David (1990): The Condition of Postmodernity: An Enquiry into the Origins of Cultural Change, Oxford: Blackwell.

Hulme, Mike (2011): "Reducing the Future to Climate: A Story of Climate Determinism and Reductionism," Osiris, The University of Chicago Press 26:1, 245-266, doi: $10.1086 / 661274$

Ideland, Malin (2019): The Eco-Certified Child: Citizenship and Education for Sustainability and Environment, [Cham]: Palgrave Macmillan.

Jenks, Chris (2005): Childhood, London: Routledge.

Kverndokk, Kyrre (2019): "Barnet og ungdomsopprøret Om Greta Thunsbergs retorikk i anledning Fritt Ords pris 2019," Salongen - nettidsskrift for filosofi og idéhistorie, [online] http://www.salongen.no/barnet-og-ungdomsopproret/ [27.08.2020].

Kverndokk, Kyrre (2020): “Talking about Your Generation: 'Our Children' as a Trope in Climate Change Discourse," Ethnologia Europaea, Open Library of Humanities 50:1, doi: 10.16995/ee.974.

Lövbrand, Eva et al. (2015): "Who Speaks for the Future of Earth? How Critical Social Science Can Extend the Conversation on the Anthropocene," Global Environmental Change, 32, 211-218, doi: 10.1016/j.gloenvcha.2015.03.012.

Lyotard, Jean-François (1986): The Postmodern Condition: A Report on Knowledge, Manchester: Manchester University Press.

Moezzi, Mithra, Kathryn B. Janda \& Sea Rotmann (2017): "Using Stories, Narratives, and Storytelling in Energy and Climate Change Research," Energy Research \& Social Science, (Narratives and Storytelling in Energy and Climate Change Research), 31, 1-10, doi: 10.1016/j.erss.2017.06.034.

Neimanis, Astrida; Åsberg, Cecilia; Hedrén, Johan (2015): "Four Problems, Four Directions for Environmental Humanities: Toward Critical Posthumanities for the Anthropocene," Ethics \& the Environment, 20:1, 67-97.

Neimanis, Astrida; Walker, Rachel Loewen (2014): "Weathering: Climate Change and the 'Thick Time' of Transcorporeality," Hypatia, 29:3, 558-575, doi: 10.1111/ hypa.12064.

Qvarsebo, Jonas (2019): "The Moral Regime of Norm Critical Pedagogics - New Ways of Governing the Swedish Pre-School Child," Critical Studies in Education, 0:0, 1-15, doi: 10.1080/17508487.2019.1596961.

Smith, Joe (2005): "Dangerous News: Media Decision Making about Climate Change Risk," Risk Analysis, 25:6, 1471-1482, doi: 10.1111/j.1539-6924.2005.00693.x.

Strandbrink, Peter (2018): "Nostalgia and Shrinkage: Philosophy and Culture under Post-Postmodern Conditions," Educational Philosophy and Theory, 50:14, 1408-1409, doi: 10.1080/00131857.2018.1462522. 


\section{Culture Unbound}

Journal of Current Cultural Research

Swyngedouw, Erik (2010): “Apocalypse Forever? Post-Political Populism and the Spectre of Climate Change," Theory, Culture \& Society, 27:2-3, 213-232, doi: $10.1177 / 0263276409358728$.

Thunberg, Greta (2019): No One Is Too Small to Make a Difference, London: Penguin Books.

Waters, Colin N. et al. (2016): "The Anthropocene Is Functionally and Stratigraphically Distinct from the Holocene," Science, 351:6269, aad2622, doi: 10.1126/science. aad2622.

Wetts, Rachel (2020): "Models and Morals: Elite-Oriented and Value-Neutral Discourse Dominates American Organizations' Framings of Climate Change," Social Forces, Oxford Academic 98:3, 1339-1369, doi: 10.1093/sf/soz027. 